\title{
Article \\ pH-Responsive Hybrid Hydrogels as Antibacterial and Drug Delivery Systems
}

\author{
Shabnam Sattari, Abbas Dadkhah Tehrani and Mohsen Adeli * \\ Department of Chemistry, Faculty of Science, Lorestan University, Khorramabad P.O. Box 465, Iran; \\ sattari_sh@yahoo.com (S.S.); a_dadkhahtehrani@yahoo.com (A.D.T.) \\ * Correspondence: m.aadeli@fu-berlin.de
}

Received: 11 April 2018; Accepted: 11 June 2018; Published: 13 June 2018

\begin{abstract}
This study describes the design and synthesis of organic-inorganic hybrid hydrogels based on an interpenetrating polymer network (IPN) composed of polyaspartic acid crosslinked by graphene nanosheets as the primary network and poly(acrylamide-co-acrylic acid) as the secondary network. Silver, copper oxide, and zinc oxide nanoparticles were formed within the gel matrix, and the obtained hydrogel was applied to a load and controlled release of curcumin. The loading of curcumin and the release of this drug from the gels depended on the nanoparticle's (NP's) content of hydrogels as well as the $\mathrm{pH}$ of the medium. The synthesized hydrogels showed antibacterial activity against $E$. coli and $S$. aureus bacteria. The ability of the synthesized hydrogels to incapacitate bacteria and their loading capacity and controlled release of curcumin qualify them for future therapies such as wound-dressing applications.
\end{abstract}

Keywords: graphene; hydrogels; interpenetrating polymer network; drug delivery; antibacterial

\section{Introduction}

In recent years, a variety of nanostructures has been developed to improve the therapeutic efficiency of drugs [1,2]. Compared to other delivery systems, polymeric hydrogels have been extensively used for this purpose. A polymer hydrogel has the capacity to swell and retain a large fraction of water within its structure that arises mainly from the presence of hydrophilic groups [1-3]. Additionally, hydrogels can control drug release due to changes (swelling, dissolution, or degradation) in the gel structure. In fact, the drug penetration and release behavior depend on hydrogel's network that can easily be tuned by crosslink density $[3,4]$. There is a growing interest to achieve a rational design of advanced hydrogels with tunable properties. The incorporation of nanoparticles into the polymer matrix is a versatile method for controlling the crosslink density of hydrogels and drug release control. A combination therapy of nanoparticles and drugs provide an effective strategy to improve the pharmacological activity and efficacy of drugs. Moreover, the hybrid systems can be useful in long-term delivery systems [5-9]. On the other hand, hydrogels can provide nanoparticles with the clinically useful formulation needed for their clinical applications. The innovative combination of polymer hydrogels and nanoparticles with entirely different properties generate not only structural diversity but also create synergistic, unique, and potentially useful properties that are not found in the individual components [10-12]. The incorporation of metal nanoparticles into polymer network (PN) hydrogels offers an excellent alternative to control the release of nanoparticles and for applications requiring higher mechanical toughness. Interpenetrating polymer network (IPN)-based hydrogels are defined as the combination of two or more polymer networks which interpenetrate within each other at the molecular level without being covalently bonded $[13,14]$. These hydrogels act as templates for a variety of loads and for the synthesis of nanoparticles smaller than 2-3 nm with a uniformly distribution $[15,16]$. 
Herein, we described the preparation and characterization of new, $\mathrm{pH}$-responsive, hybrid hydrogels made from polyaspartic-acid-based, interpenetrating network (IPN) hydrogel nanocomposites using 2D graphene nanosheets, nanoparticles (NPs), and acrylic copolymers as antibacterial and drug delivery systems. In the first step, polyaspartic acid hydrogel was synthesized by the combination of polysuccinimide (PSI) and GO-NH $\mathrm{N}_{2}$ as the primary link crosslinking agents. The interaction of PSI polymers chains with GO-NH$H_{2}$ leads to the formation of a polyaspartic acid hydrogel. Polyaspartic acid (PAsp), which has a protein-like structure, is an appropriate candidate for the preparation of hydrogels because of its biodegradation and biocompatibility properties $[17,18]$. This polyanionic hydrogel contains ionizable groups that exhibit high sensitivity to $\mathrm{pH}$ variations. In the next step, acrylic monomers were polymerized onto and into the PAsp hydrogel by $N, N^{\prime}$-methylenebisacrylamide (NMBA) as secondary link crosslinking agents. Finally, different metal nanoparticles including Ag NPs, $\mathrm{CuO}$ NPs, and ZnO NPs were formed inside the network by physically embedding them into the hydrogel matrix. The IPNs showed an excellent loading capacity for curcumin as well as antibacterial activity against Gram-positive and Gram-negative bacteria. The release profile of curcumin depended on the embedded metal nanoparticles and the medium conditions. Collectively, our results showed that such systems can be considered as an attractive and promising formulation for various biomedical applications such as a wound dressing, and they can generate a step forward in applications for skin.

\section{Experimental}

\subsection{Materials}

$N, N^{\prime}$-methylenebisacrylamide (NMBA) (99\%), graphite powder, N-hydroxysuccinimide (NHS) (98\%), $N, N^{\prime}$-dicyclohexylcarbodiimide (DCC) $(99 \%)$, ethylenediamine (EDA) ( $\left.\geq 99 \%\right)$, L-aspartic acid $(\geq 98 \%$ ), and curcumin (Cur) ( $\geq 94 \%$ ) were purchased from Sigma-Aldrich (Steinheim, Gemany). Silver nitrate $\left(\mathrm{AgNO}_{3}\right)$, zinc nitrate hexahydrate $\left(\mathrm{Zn}\left(\mathrm{NO}_{3}\right)_{2} \cdot 6 \mathrm{H}_{2} \mathrm{O}\right)(98 \%)$, copper(II) chloride $\left(\mathrm{CuCl}_{2}\right)$, acrylamide (Am) (99\%), acrylic acid (AA) (98\%), and all other reagents and solvents were purchased from Merck (Kenilworth, NJ, USA) and used as received. Staphylococcus aureus (PTCC 1112, Pasteur Institute, Tehran, Iran) and Escherichia coli (PTCC 1330, Pasteur Institute, Tehran, Iran) were used for the antimicrobial tests.

\subsection{Methods}

The Fourier transform infrared (FTIR) spectra of samples were recorded at room temperature using a Shimadzu FT-IR 8400 spectrometer (Kyoto, Japan) with a KBr pellet at a scanning range from 4000 to $500 \mathrm{~cm}^{-1}$ and a weight ratio of $5 / 200 \mathrm{mg}$. All UV-visible spectra were recorded at room temperature for well-dispersed nanocomposite samples in the wavelengths ranging from 400 to 800 nm using a Shimadzu UV-Vis 1650 PC spectrophotometer (Kyoto, Japan). Thermogravimetric analysis (TGA) was performed using STA409 apparatus (Linsei) from $25^{\circ} \mathrm{C}$ to $900^{\circ} \mathrm{C}$ at a scan rate of $10^{\circ} \mathrm{C} / \mathrm{min}$ in a nitrogenous atmosphere. X-ray diffraction (XRD, PANalytical company, Almelo, the Netherlands) patterns of hydrogels were recorded with a Siemens diffractometer using $\mathrm{Cu}-\mathrm{k}$ radiation at $35 \mathrm{kV}$ in the scan range of $2 \theta=2^{\circ}$ to $90^{\circ}$. For SEM (TESCAN company, Brno, Czech Republic) characterization, the hydrogel samples were freeze-dried and then kept overnight in a vacuum chamber to remove excess solvent. Then, the SEM pictures were taken by a LEO 440 i scanning electron microscope after a gold coating. Statistical analysis was performed upon 100 nanoparticles randomly selected at $89 \mathrm{kX}$ magnification. The diameter of the nanoparticles was calculated using measurement software.

\subsection{Preparation of Poly(succinimide) (PSI)}

Polysuccinimide (PSI) was synthesized through a polycondensation process according to the previously reported procedure in literature [19]. Briefly, L-aspartic acid and o-phosphoric acid (85\%) in a weight ratio of 1:1 were placed into an electric thermostatic drying oven for $4.5 \mathrm{~h}$ at $180-200{ }^{\circ} \mathrm{C}$. 
The reaction mixture was then cooled and dissolved in dimethylformamide (DMF). The resulting solution was precipitated by adding methanol as a nonsolvent, washed thoroughly with distilled water, and dried under vacuum at $65^{\circ} \mathrm{C}$ for two days. (Yield $87 \%$ ).

\subsection{Synthesis of Graphene Oxide (GO)}

Graphene oxide was prepared through the improved Hummers' method [20] by the slow addition of graphite $(3 \mathrm{~g})$ to a mixture of $\mathrm{H}_{2} \mathrm{SO}_{4}(360 \mathrm{~mL})$ and $\mathrm{H}_{3} \mathrm{PO}_{4}(40 \mathrm{~mL}) . \mathrm{KMnO}_{4}(18 \mathrm{~g})$ was added to the reaction system slowly upon stirring for $1 \mathrm{~h}$. Then, the reaction was heated to $50{ }^{\circ} \mathrm{C}$ and stirred for an additional $24 \mathrm{~h}$. Afterwards, distilled water $(400 \mathrm{~mL})$ with $30 \% \mathrm{H}_{2} \mathrm{O}_{2}(15 \mathrm{~mL})$ was injected into the reaction system to terminate the reaction. The GO was separated by filtration and washed with $5 \%$ hydrochloric acid and distilled water. The product was dried at $40{ }^{\circ} \mathrm{C}$ for $72 \mathrm{~h}$ (yield $70 \%$ ).

\subsection{Synthesis of GO-NH}

Amine-functionalized GO was synthesized using EDA as reported in literature [21]. Briefly, NHS (11 mmol) and DCC (10 mmoL) were added into the homogeneous dispersion of GO (0.1 g) in DMF, and the mixture was stirred in a water bath at $50^{\circ} \mathrm{C}$ for $1 \mathrm{~h}$. Finally, EDA $(50 \mathrm{mmoL})$ was added and the reaction mixture was refluxed and stirred continuously for $24 \mathrm{~h}$ at $80^{\circ} \mathrm{C}$ to obtain amine-functionalized $\mathrm{GO}\left(\mathrm{GO}-\mathrm{NH}_{2}\right)$. The suspension was centrifuged and washed several times with ethanol to remove excess EDA. The product was dried in a vacuum oven at $40{ }^{\circ} \mathrm{C}$ for $48 \mathrm{~h}$ (yield $85 \%$ ).

\subsection{Preparation of IPN Hydrogel}

Amino-functionalized GO was used as a modifier and a crosslinking agent to interconnect the PSI chains. PSI ( $0.5 \mathrm{~g})$ was dissolved in DMF $(5 \mathrm{~mL})$, followed by the addition of GO-NH $\mathrm{NH}_{2}(0.005 \mathrm{~g})$. The reaction mixture was stirred continuously at $40{ }^{\circ} \mathrm{C}$ for $24 \mathrm{~h}$. Then, the aqueous solution of monomers (14 mmol of AA and $14 \mathrm{mmoL}$ of Am) was added to the above hydrogel. After nitrogen bubbled for $30 \mathrm{~min}$, polymerization was carried out using NMBA $(2 \%(w / w))$ and APS $(2 \%(w / w))$ as a crosslinker and an initiator, respectively. The obtained hydrogels were placed in $50 \mathrm{~mL}$ of $0.1 \mathrm{M} \mathrm{NaOH}$ aqueous solution for $24 \mathrm{~h}$ and then immersed in water for two days to open the remaining succinimide units and to remove unreacted monomers. Finally, the prepared hydrogel was dried in a vacuum oven at $50^{\circ} \mathrm{C}$.

PAsp hydrogels were also synthesized according to the procedure described above. In short, $0.5 \mathrm{~g}$ of PSI was dissolved in DMF $(10 \mathrm{~mL})$, followed by the addition of $0.005 \mathrm{~g}$ of $\mathrm{GO}-\mathrm{NH}_{2}$. The reaction mixture was stirred continuously at $40{ }^{\circ} \mathrm{C}$ for $24 \mathrm{~h}$. The obtained hydrogels were placed in $50 \mathrm{~mL}$ of $0.1 \mathrm{M} \mathrm{NaOH}$ aqueous solution for $24 \mathrm{~h}$, followed by an immersion in water for two days. Finally, the prepared hydrogel was dried in a vacuum oven at $50^{\circ} \mathrm{C}$.

\subsection{Preparation of Nanoparticle-Embedded IPN Hydrogels}

Due to their negative charges, hydrogels interact with metal ions electrostatically. AgNP-embedded, IPN hydrogel was synthesized according to a previously reported technique using $\mathrm{NaBH}_{4}$ as a reducing agent [22]. Accurately weighed, dried, IPN hydrogels were equilibrated with water for $48 \mathrm{~h}$. The swollen hydrogels were immersed in a beaker containing $\mathrm{AgNO}_{3}$ aqueous solution with different concentrations $(0.3,0.5$, and $1 \mathrm{mmoL})$ and then allowed to equilibrate for one day to entrap the silver ions $\left(\mathrm{Ag}^{+}\right)$. Finally, in order to reduce the silver ions to silver nanoparticles, these IPN hydrogel-loaded silver salts were placed in a cold aqueous solution of $\mathrm{NaBH}_{4}$ for $3 \mathrm{~h}$. Changing the color of the hydrogel to brown upon the reduction of silver ions confirmed the formation of silver nanoparticles (Figure S1).

The $\mathrm{ZnO}$ and $\mathrm{CuO}$ nanoparticle-embedded IPN hydrogel was synthesized using $\mathrm{NaOH}$ as an oxidizing agent. Typically, the swollen hydrogel was added into copper chloride and zinc nitrate solutions with different concentrations $(0.000,0.3,0.5$, and $1 \mathrm{~mm})$ for $24 \mathrm{~h}$. After washing with distilled 
water, the hydrogels were placed in $50 \mathrm{~mL} \mathrm{NaOH}(0.1 \mathrm{M})$ solution for $24 \mathrm{~h}$ in order to prepare $\mathrm{ZnO}$ and $\mathrm{CuO}$ NPs. Table 1 describes the different formulations used in this work.

\subsection{Swelling Studies}

Swelling studies were conducted on IPN hydrogel and NP-embedded IPN hydrogels through the gravimetric method by the immersion of a definite amount of dried hydrogel samples in the solutions of different temperatures $\left(25^{\circ} \mathrm{C}-90^{\circ} \mathrm{C}\right)$ and $\mathrm{pH}$ values (7.4 and 2.1). The swelling ratio (\% SR) was calculated by the following equation:

$$
\mathrm{SR}(\%)=W_{\mathrm{t}}-W_{0} / W_{0} \times 100
$$

where $W_{\mathrm{t}}$ was the sample weight at time $\mathrm{t}$ and $W_{0}$ was the initial weight of the sample.

\subsection{In Vitro Drug Loading and Release Studies}

Curcumin was loaded by nanoparticle-embedded hydrogels through a swelling-diffusion approach. To load curcumin into the hydrogels, dry hydrogels $(0.5 \mathrm{~g})$ were soaked in $50 \mathrm{~mL}$ of curcumin solution $(5 \mathrm{mg} / 50 \mathrm{~mL}, 2: 8$ ethanol:distilled water) under shaking in the dark at room temperature for $24 \mathrm{~h}$. Then, the hydrogels were rinsed thoroughly with distilled water to remove the surface-adsorbed curcumin. The loading capacity was calculated according to the following Equation (2):

$$
\text { Drug loading efficiency }(\%)=W_{\mathrm{e}} / W_{0} \times 100
$$

where $W_{\mathrm{e}}$ and $W_{0}$ are the weight of the drug in the hydrogel and weight of the initial drug, respectively.

The drug release profiles of curcumin-loaded hydrogels were investigated at different $\mathrm{pHs}$ (2.1 and 7.4) at $37^{\circ} \mathrm{C}$. The amount of released curcumin was quantified by UV/Vis spectrophotometry at $430 \mathrm{~nm}$ using a curcumin standard calibration curve. The percentages of drug released were calculated by the following equation:

$$
\text { Drug release }(\%)=M_{t} / M_{0} \times 100
$$

where $M_{\mathrm{t}}$ and $M_{0}$ are the amount of curcumin released at time and the amount of curcumin loaded into the hydrogels, respectively.

The NP release profiles of hydrogels were investigated at $\mathrm{pH} 7.4$ at $37^{\circ} \mathrm{C}$. The absorbance of $\mathrm{Ag}, \mathrm{CuO}$, and $\mathrm{ZnO}$ NPs were recorded at 421,280 , and $349 \mathrm{~nm}$ wavelengths respectively, by $\mathrm{UV} / \mathrm{Vis}$ spectrophotometry at different times.

\subsection{Antibacterial Activity}

The antibacterial properties of IPNs samples were evaluated by the colony-counting method (CFU) by using Escherichia coli (E. coli) Gram-negative bacteria and Staphylococcus aureus (S. aureus) Gram-positive bacteria as model organisms [23]. Monocolonies of E. coli and S. aureus were cultured on liquid luria-bertani (LB) culture medium $(20 \mathrm{~mL})$ and were kept in an incubator at $37^{\circ} \mathrm{C}$ for $12 \mathrm{~h}$. The bacteria were diluted with phosphate-buffered saline (PBS) to $10^{6}-10^{7} \mathrm{CFU} \mathrm{ml}{ }^{-1}$. Next, $20 \mathrm{mg}$ of the samples was mixed with $1 \mathrm{~mL}$ E. coli and S. aureus bacteria solution in the dark for $30 \mathrm{~min}$. Then, $150 \mu \mathrm{L}$ of the suspension was spread on LB agar plates, and the colonies were counted after $12 \mathrm{~h}$ incubation at $37^{\circ} \mathrm{C}$ to estimate the loss of viability of E. coli and S. aureus cells on the samples.

\section{Results and Discussion}

The use of IPN hydrogels for the stabilization of nanoparticles and drug delivery is well-established and has attracted great attention in the scientific community [24]. In this context, IPN hydrogels composed of a PAsp network, acrylic polymer gel, metal nanoparticles, and graphene were prepared and used as a drug delivery method and as antibacterial systems. The synthesis of IPN hydrogel is schematically presented in Scheme 1. 
The compositions and physicochemical properties of IPNs were changed by variations in the synthetic parameters (Table 1).

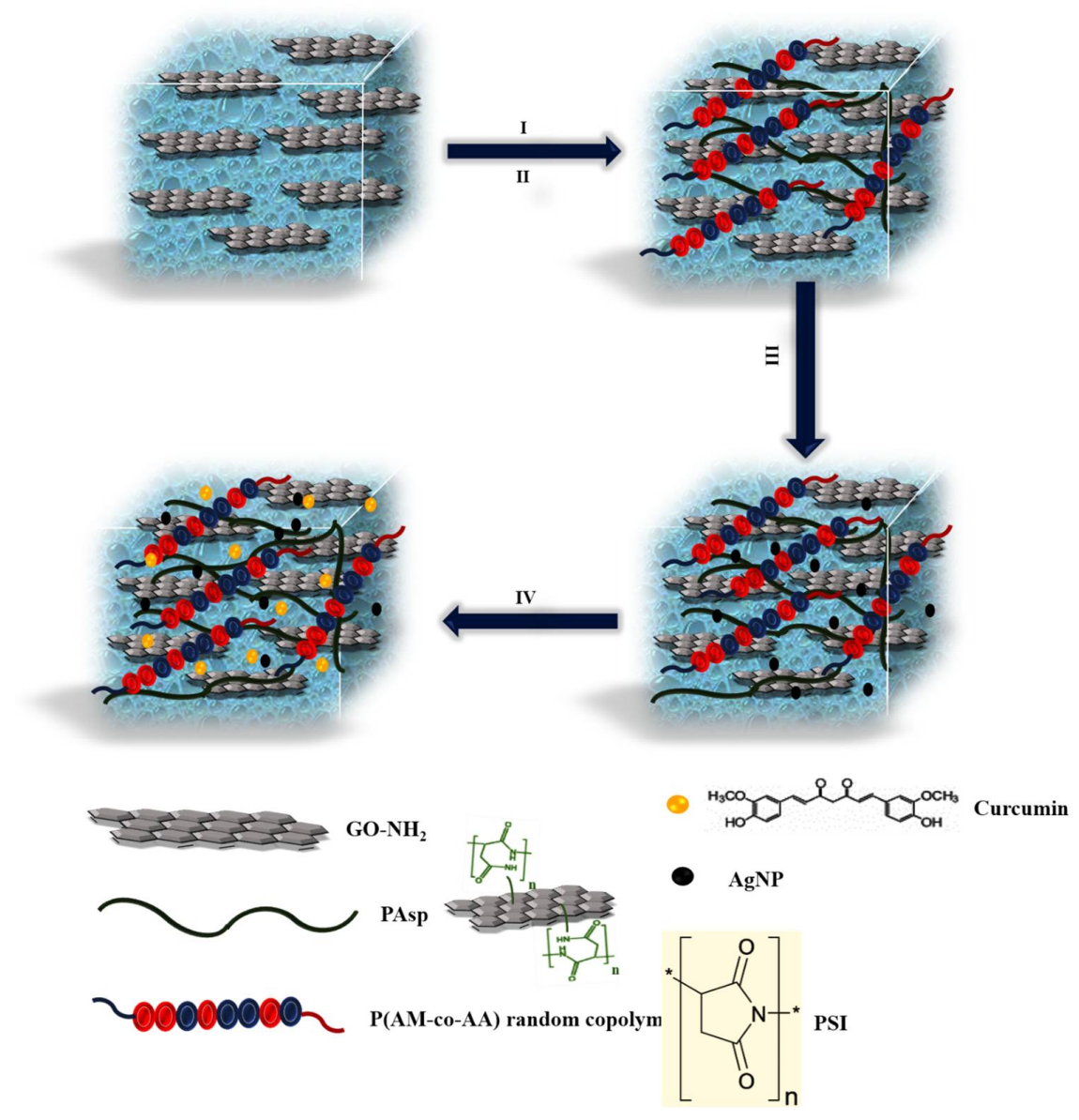

Scheme 1. Representation of the synthesis of interpenetrating polymer network (IPN) nanoparticles (NPs). I) Reaction of the polysuccinimide (PSI) and graphite oxide (GO)- $\mathrm{NH}_{2}$ to the formation of a polyaspartic acid (PAsp) hydrogel, II) Polymerization of acrylic monomers onto and into the PAsp hydrogel, III) The formation of $\mathrm{Ag}, \mathrm{CuO}$, or $\mathrm{ZnO}$ nanoparticles inside the hydrogels, and IV) Loading of the drug inside the hydrogels.

Table 1. Compositions of different IPN hydrogels synthesized and investigated in this work.

\begin{tabular}{|c|c|c|c|c|c|c|}
\hline Formulation Code & Am (mmoL) & AA (mmoL) & PSI (g) & $\mathrm{AgNO}_{3}(\mathrm{mmoL})$ & $\mathrm{CuCl}_{2}(\mathrm{mmol})$ & $\mathrm{Zn}\left(\mathrm{NO}_{3}\right)_{2} \cdot 6 \mathrm{H}_{2} \mathrm{O}(\mathrm{mmoL})$ \\
\hline IPN0 & 0.05 & 0.06 & 0.1 & - & - & - \\
\hline IPN1 & 0.05 & 0.06 & 0.1 & 0.3 & - & - \\
\hline IPN2 & 0.05 & 0.06 & 0.1 & 0.5 & - & - \\
\hline IPN4 & 0.05 & 0.06 & 0.1 & - & 0.3 & - \\
\hline IPN5 & 0.05 & 0.06 & 0.1 & - & 0.5 & - \\
\hline IPN6 & 0.05 & 0.06 & 0.1 & - & 1 & - \\
\hline IIPN9 & 0.05 & 0.06 & 0.1 & - & - & 1 \\
\hline
\end{tabular}

IPN hydrogels were characterized using different spectroscopy and microscopy methods as well as thermal analysis. The IR spectrum of GO (Figure 1Aa) shows stretching vibrations at $3357 \mathrm{~cm}^{-1}$, $1728 \mathrm{~cm}^{-1}, 1627 \mathrm{~cm}^{-1}, 1236 \mathrm{~cm}^{-1}$, and $1028 \mathrm{~cm}^{-1}$, which correspond to the vibration of hydroxyl, carbonyl, $\mathrm{C}=\mathrm{C}, \mathrm{C}-\mathrm{O}$, and $\mathrm{C}-\mathrm{O}-\mathrm{C}$, respectively [25]. Significant changes were observed in the IR spectrum of GO upon functionalization with ethylenediamine (Figure $1 \mathrm{Ab}$ ). The disappearance of 
the epoxy peak at $1028 \mathrm{~cm}^{-1}$ and the appearance of new peaks at $1639 \mathrm{~cm}^{-1}$ (assigned to amidic carbonyl groups), $1541 \mathrm{~cm}^{-1}$ (corresponded to $\mathrm{N}-\mathrm{H}$ stretching vibrations in the $\mathrm{C}-\mathrm{NH}$ group), and $1195 \mathrm{~cm}^{-1}$ (assigned to $\mathrm{C}-\mathrm{N}$ stretching vibrations in the $-\mathrm{C}-\mathrm{NH}-\mathrm{C}-$ group) in the IR spectrum of GO- $\mathrm{NH}_{2}$ confirmed the successful conjugation of ethylenediamine to both the epoxide and carboxylic acid groups of GO [26]. The IR spectrum of PSI represented absorption bands at $3624 \mathrm{~cm}^{-1}, 1770 \mathrm{~cm}^{-1}$, $1710 \mathrm{~cm}^{-1}, 1394 \mathrm{~cm}^{-1}$, and $1361 \mathrm{~cm}^{-1}$ which are related to $\mathrm{NH}-$, cyclic imide, $-(\mathrm{OC})_{2} \mathrm{~N}-, \mathrm{C}-\mathrm{O}$, $-(\mathrm{OC})_{2} \mathrm{~N}-, \mathrm{C}-\mathrm{N}$, and $(\mathrm{C}=\mathrm{O})-\mathrm{NH}$ groups, respectively [19]. (1HNMR of PSI is shown in Figure S2. In this spectrum, the signal at $5.26 \mathrm{ppm}$ corresponded to the methine proton (a) and the signals of methylene proton (b) appeared at 3.2 and $2.7 \mathrm{ppm}$. The obtained results from IR and ${ }^{1} \mathrm{HNMR}$ confirmed the successful synthesis of PSI).

In comparison with the IR spectrum of PSI, PAsp hydrogel showed two new absorbance bands centered at $1645 \mathrm{~cm}^{-1}$ that corresponded to the vibration of the new amidic $\mathrm{C}=\mathrm{O}$ groups. These new carbonyl groups were created by the reaction between $\mathrm{GO}-\mathrm{NH}_{2}$ and the imide ring of PSI. The aforementioned results in combination with the disappearance of absorbance bands at $1716 \mathrm{~cm}^{-1}$ and $1799 \mathrm{~cm}^{-1}$ (assigned to the succinimide groups) in the IR spectrum of PAsp hydrogel confirmed the successful aminolysis of PSI by GO-NH ${ }_{2}$ [27]. The IR spectrum of IPN0 hydrogels (Figure 1Ae) indicated that this hydrogel was combined with PAm, PAA, and PAsp. Two absorbance bands around $2800 \mathrm{~cm}^{-1}$ and $2900 \mathrm{~cm}^{-1}$ (assigned to methyl groups) overlapped with an absorbance band at $3427 \mathrm{~cm}^{-1}$ which corresponded to the carboxyl groups. This confirmed the successful polymerization of the acrylic copolymer (AA- Am) within the PAsp hydrogel. In addition, characteristic peaks at $1668 \mathrm{~cm}^{-1}$ ( $\mathrm{C}=\mathrm{O}$ stretching of amide group), $1725 \mathrm{~cm}^{-1}$ ( $\mathrm{C}=\mathrm{O}$ stretching of carboxyl group), $1598 \mathrm{~cm}^{-1}$ (COO ${ }^{-}$asymmetric stretching), $1411 \mathrm{~cm}^{-1}$ (COO-symmetric stretching mode), and $1450 \mathrm{~cm}^{-1}$ (C-H bending) could be observed in the IR spectra of the IPN0 hydrogels. This result proved that PAm and PAA had been successfully polymerized in the hydrogel networks [28].

XRD was used to investigate the crystal structure of materials. The XRD diagram of the GO nanosheets revealed a peak at about $2 \theta=11.87^{\circ}$, which corresponded to the oxidation of graphite powder [21]. However, after the grafting of amino groups, the intensity of this peak was significantly reduced and another broad peak of graphite at $2 \theta$ value $20.6^{\circ}$ appeared, which indicated a slight reduction of GO by ethylenediamine [26]. The absence of the graphene oxide diffractions in the IPN0 hydrogel and the changes in crystal structure of graphene oxide after forming the PAsp hydrogel implied a uniform dispersion of the graphene sheets in the hydrogel (Figure 1Bc). This was due to a reaction between the amino groups of $\mathrm{GO}-\mathrm{NH}_{2}$ and the succinimide units of the PSI chains. Also, the broad peaks observed in the IPN0 hydrogel (Figure 1Bc) at $22^{\circ}$ were assigned to the polymeric matrix. The embedding of metal nanoparticles into the IPN hydrogels was evaluated by XRD. Figure 1B shows the X-ray powder diffraction pattern of the IPN3, IPN6, and IPN9 NP hydrogels. The sharp peaks in IPN NP hydrogels, indicating the crystalline character of the materials, can be assigned to reflections from characteristic crystal planes of the NPs. IPN3 hydrogel exhibited sharp and intense peaks at $38.35^{\circ}, 44.54^{\circ}, 64.75^{\circ}$, and $77.63^{\circ}$ (Figure 1Bd), which were attributed to (111), (200), (220), and (311) Bragg's reflections of the silver nanoparticles, respectively $[29,30]$. The XRD pattern of CuO NPs displayed characteristic peaks at $2 \theta$ of $29.41^{\circ}, 34.95^{\circ}, 38.11^{\circ}, 48.12^{\circ}, 57.87^{\circ}, 61.48^{\circ}, 65.64^{\circ}, 67.72^{\circ}$ and $74.94^{\circ} \mathrm{C}$ corresponding to (110), (002), (111), (102), (113), (311), (113), (311), and (004) planes of CuO NPs, respectively (Figure 1Be) [31,32].

In addition, the XRD pattern of the $\mathrm{ZnO} N P s$ displayed characteristic peaks at $2 \theta$ of $31.76^{\circ}, 34.37^{\circ}$, $36.13^{\circ}, 47.42^{\circ}, 56.63^{\circ}, 62.91^{\circ}$, and $67.95^{\circ}$ assigned to (100), (002), (101), (102), (110), (103), and (112) planes of zinc oxide (Figure 1Bf) [33,34]. These results confirmed the formation of crystalline NPs into IPN hydrogels. The sharp peaks indicated the crystalline character of the material. Also, the broad diffraction observed in the XRD patterns of IPN1, IPN4, and IPN7could be completely attributed to the amorphous nature of the polymer chains (Figure S3). The formation of NPs within the hydrogel networks was further investigated by UV-Vis analysis. IPN1, IPN4, and IPN7 exhibited significant absorption peaks centered at 421,280 , and $349 \mathrm{~nm}$ wavelengths due to the surface plasmon resonance 
of $\mathrm{Ag}, \mathrm{CuO}$, and $\mathrm{ZnO}$ NPs, respectively. Moreover, a small hump at $280 \mathrm{~nm}$ in the absorption spectrum of IPN1 could be attributed to ionic silver or charged clusters. This result confirmed the presence of embedded metal nanoparticles in the structure of hydrogels and is in agreement with previously published papers [35-37].
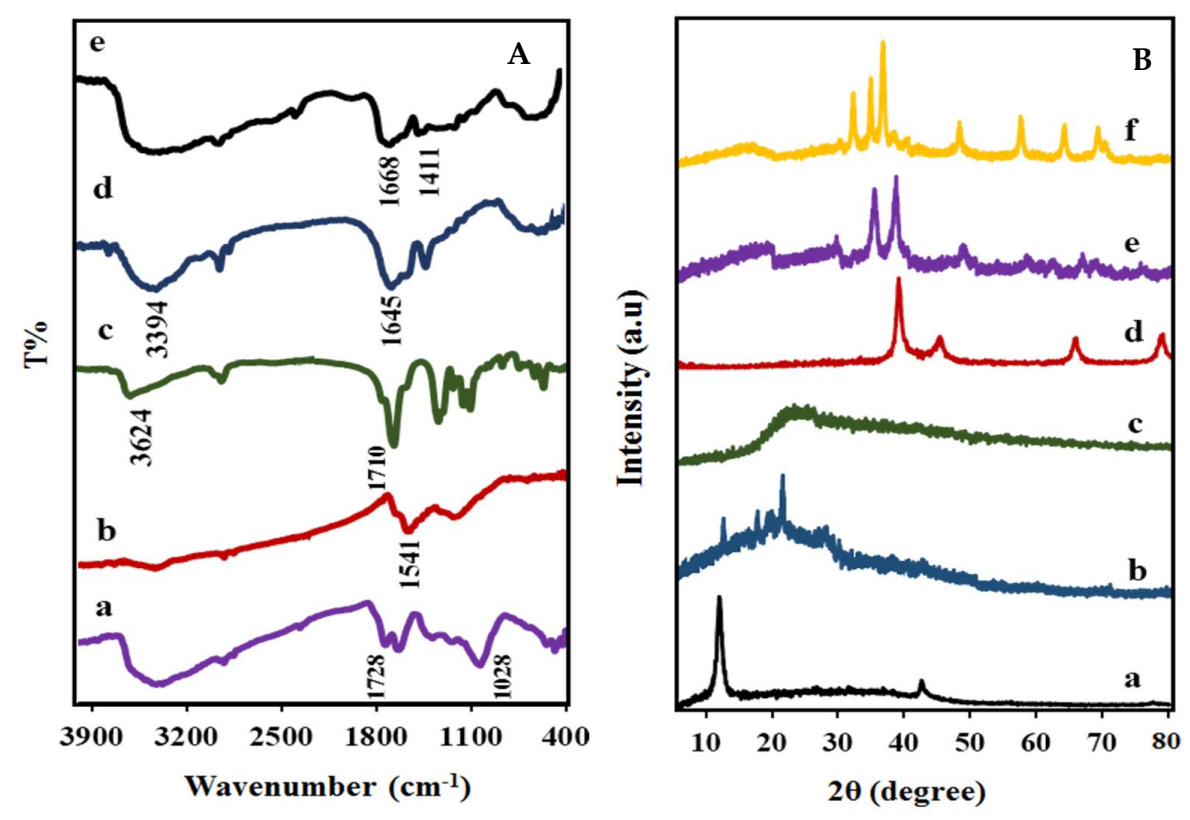

Figure 1. (A) IR spectra of (a) GO, (b) GO-NH2, (c) PSI, (d) PAsp hydrogel and (e) IPN0 hydrogel; (B) X-ray diffraction pattern of (a) GO, (b) GO-NH 2 (c) IPN0 hydrogel, (d) IPN3, (e) IPN6, and (f) IPN9 NP hydrogel.

The thermal behavior of GO and the synthesized hydrogels was investigated by TGA (Figure 2B). The initial weight loss at temperatures less than $100{ }^{\circ} \mathrm{C}$ was attributed to the evaporation of entrapped water in GO and the hydrogels. GO was thermally unstable and mainly showed mass loss ( 45\%) at $200{ }^{\circ} \mathrm{C}$, which is ascribed to the removal of $\mathrm{H}_{2} \mathrm{O}$ and the pyrolysis of labile oxygen containing functional groups [38]. This result showed that the prepared GO was strongly oxidized. The decomposition onset temperature of GO increased to $220^{\circ} \mathrm{C}$ and weight loss was mainly observed at $220-500{ }^{\circ} \mathrm{C}$ when it was embedded in PAsp hydrogel. The higher thermal stability of GO in the hydrogel was due to a slight reduction of sheets by ethylenediamine and their crosslinking by PSI. The temperature of the pyrolysis of the IPN0 hydrogel increased, and it revealed two major weight losses in the range of $250-360{ }^{\circ} \mathrm{C}$ and $360-460{ }^{\circ} \mathrm{C}$ which were due to the decomposition of the PAsp hydrogel and the acrylic copolymer chains, respectively. On the contrary, the maximum decomposition temperatures (Tmax) of the hydrogels, which were determined from the peak temperature in the differential thermogravimetric (DTG) curves, were 280, 320, 412, 415, and 420 for the PAsp hydrogel, IPN0, IPN2, and IPN8, respectively (Figure S4). These results indicated that the thermal stability of the hydrogel was increased by the incorporation of NPs. Moreover, the high char yield, which was up to $48.8,27.5$, and $33.3 \mathrm{wt} \%$ at $900{ }^{\circ} \mathrm{C}$, was observed in the thermogram of the IPN2, IPN5, and IPN8 hydrogels, respectively. This could be attributed to the metal nanoparticles inside the hydrogels.

Raman spectroscopy provides a powerful and nondestructive method to investigate the structure and integrity of carbon-based nanomaterials. The Raman spectra of GO, $\mathrm{RGO}-\mathrm{NH}_{2}$, and the PAsp hydrogel are shown in Figure 2C. The spectrum of GO showed peaks at $1587 \mathrm{~cm}^{-1}$ and $1322 \mathrm{~cm}^{-1}$; these are called $G$ bands, which originated from the first-order scattering of the E2g phonons of the $\mathrm{sp}^{2}$-hybridized carbon atoms, and D bands, which are attributed to the k-point phonons of $\mathrm{A} 1 \mathrm{~g}$ symmetry of the defects involved in the sp3-hybridized carbon bonds, respectively. The intensity 
ratio of $\mathrm{D}$ band to $\mathrm{G}$ band $\left(\mathrm{I}_{\mathrm{D}} / \mathrm{I}_{\mathrm{G}}\right)$ as a measure of the graphitization degree of carbon materials is usually used to determine how a modification disrupts the structure of graphite. The $G$ and $D$ mode of RGO-NH 2 showed blue and red shifts to $1590 \mathrm{~cm}^{-1}$ and $1309.20 \mathrm{~cm}^{-1}$, respectively. A shift in $\mathrm{G}$ peak and a slight increase in the D/G-ratio of GO- $\mathrm{NH}_{2}(1.16)$ compared to GO (1.15) suggests that the $\mathrm{sp}^{2}$ structure of graphene sheets was destructed to a high extend. These defects could be attributed to the restoration of $\mathrm{sp}^{2}$ as new graphitic domains with a smaller size than the ones present in GO [21]. Also, when GO-NH$H_{2}$ was embedded in PAsp, the G-band shifted to $1598 \mathrm{~cm}^{-1}$ and the $\mathrm{I}_{\mathrm{D}} / \mathrm{I}_{\mathrm{G}}$ ratio increased (1.25) in comparison with $\mathrm{GO}-\mathrm{NH}_{2}$ (1.16). This result was due to the increase in the number of $\mathrm{sp}^{3}$ carbons upon chemical functionalization. These results in addition to the appearance of an additional weak shoulder at $1340 \mathrm{~cm}^{-1}$, which was assigned to PAsp moieties, confirmed the grafting of the PAsp on the $\mathrm{GO}-\mathrm{NH}_{2}$ surfaces.
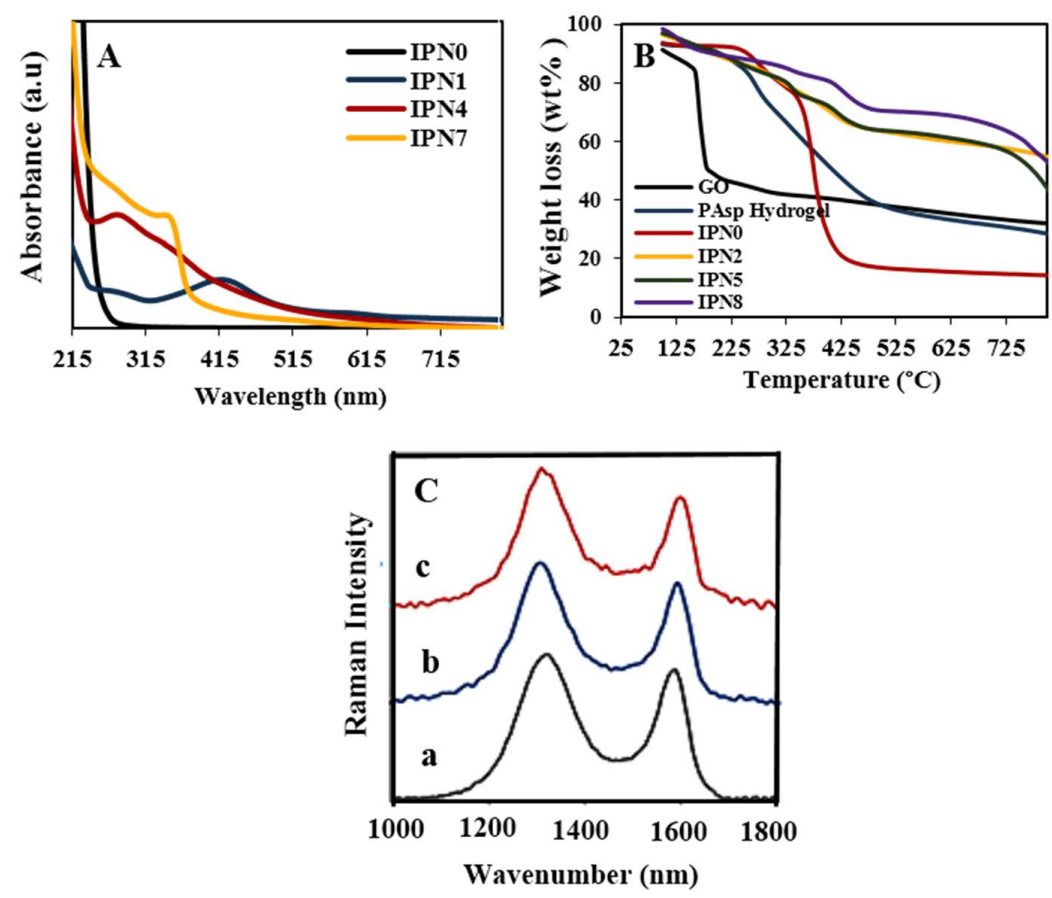

Figure 2. (A) UV-visible spectral analysis of IPN0 hydrogel, IPN1, IPN4, IPN7; (B) TGA thermograms of GO, PAsp hydrogel, IPN0, IPN2, IPN5, and IPN8 NP hydrogel; (C) Raman spectra of (a) GO, (b) GO-NH${ }_{2}$, and (c) PAsp hydrogel.

SEM measurements were used to evaluate the surface and interior morphology of synthesized hydrogels. The SEM images of PAsp, IPN, and three IPN NP hydrogels are shown in Figure 3. A network structure with a large number of pores and an average size of less than $500 \mathrm{~nm}$ in length was observed in the PAsp hydrogel. These pores are attributed to the formation of a 3D network in PSI by GO- $\mathrm{NH}_{2}$ as a crosslinking agent (Figure 3a). The IPN0 hydrogel showed a uniform, porous structure with an approximate pore size (e.g., $200 \pm 8 \mathrm{~nm}$ ) which would be suitable for the formation of nanoparticles and drug loading (Figure 3b,c). The difference between the morphology of PAsp and IPN0 hydrogels probably originated from the interactions between the networks during the polymerization processes. SEM images further revealed the formation of nanoparticles in the IPN hydrogels. SEM images of the IPN NP hydrogels showed a homogeneous distribution of the NPs through the hydrogel matrix when the swollen hydrogels were placed into the silver nitrate, $\mathrm{Zn}$ nitrate solution. Aggregations or clusters of NPs were not observed because they stabilized through the interfacial interactions with the carboxyl groups of the hydrogel matrixes. During this process, most of the ions were loaded into free-network spaces of the hydrogel. Also according to the results of the SEM images (Figure S4), almost no distinguishable difference was found in the NP size for the 
hydrogels with different contents of $\mathrm{AgNO}_{3}, \mathrm{CuCl}_{2}$, and $\mathrm{Zn}(\mathrm{NO})_{3} \cdot 6 \mathrm{H}_{2} \mathrm{O}$. This is probably due to the optimization of the amount of polysuccinimide (PSI) and the acrylic acid monomer (Figure S5). Energy Dispersive X-Ray Spectroscopy (EDX) analysis showed peaks at 3, 1, and $1 \mathrm{keV}$ for the IPN NP hydrogels (Figure 3) that corresponded to the AgNPs, CuONPs, and ZnONPs and their surface plasmon resonance. This is in agreement with previously published papers [39-41].
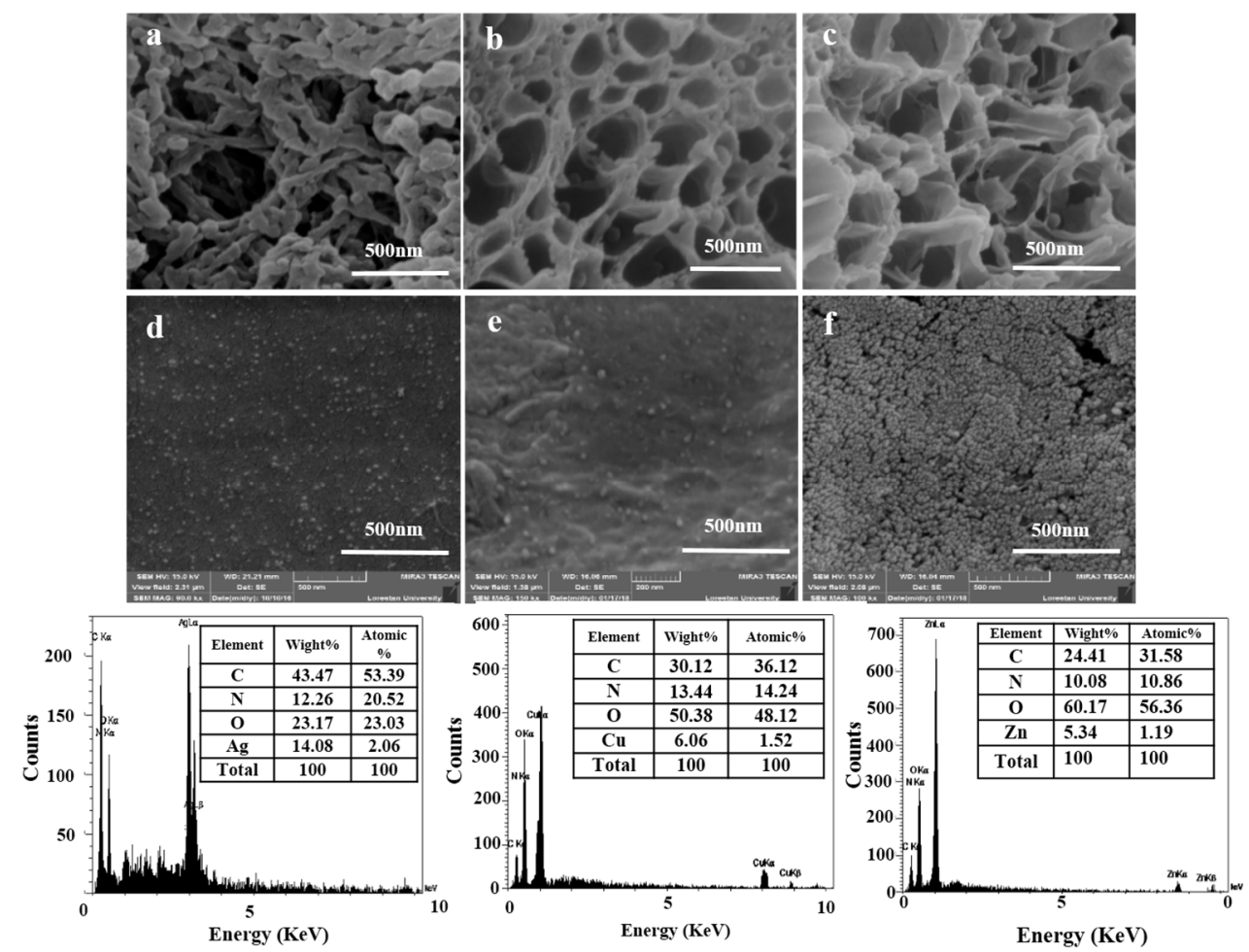

Figure 3. SEM images of (a) PAsp hydrogel; $(\mathbf{b}, \mathbf{c})$ IPNO hydrogel; SEM images and EDX diagram (d) IPN2; (e) IPN4; (f) IPN7 hydrogel.

The swelling behavior of hydrogels is a crucial factor to evaluate their capability to absorb and release drugs [42]. Therefore, the swelling behaviors of the synthesized hydrogels were investigated in various environmental conditions (Figure 4 and Figure S6). The hydrogels showed similar swelling profiles. Figure S7 shows the swelling behavior of IPNs as a function of time. The plotted curves in Figure S6 showed that IPNs have similar swelling behavior with a relatively slower saturation after $8 \mathrm{~h}$. In order to study the effect of the $\mathrm{pH}$ of the medium on the swelling characteristics of hydrogels, the swelling test of the IPN hydrogels before and after the formation of NPs was accomplished at $\mathrm{pH}$ 2.1 and 7.4 at $37^{\circ} \mathrm{C}$ (Figure 4a,b). At pH 2.1, the swelling ratios were not significant for all hydrogels. This is attributed to the formation of hydrogen bonds between carboxyl, amine, and amide bonds in the hydrogels, which reduced their interaction with water molecules. However, at pH 7.4, the swelling ratio significantly increased in the first $30 \mathrm{~min}$ of immersion into water and reached a maximum constant swelling after 8-12 h. This is due to the repulsion between negatively charged carboxyl groups at neutral $\mathrm{pH}$, causing bigger pore sizes. Most significantly, IPN NP hydrogels exhibited a higher water-absorbing capacity than the IPN0 hydrogel at pH 7.4, probably due to the decreased crosslink density and enlargement of the hydrogel networks in the presence of NPs which resulted in an increased degree of hydration and higher water penetration. The formation of nanoparticles in the hydrogel networks may have caused an increase in the pore size and space inside the hydrogel (Figure S8) [43-45]. The swelling curves of the hydrogels at different temperatures $\left(25-90{ }^{\circ} \mathrm{C}\right)$ are also shown in Figure 4c. There was a direct correlation between the swelling ratios of the IPN hydrogels and the environmental temperature at a $25-60{ }^{\circ} \mathrm{C}$ range. However, temperatures higher than $60{ }^{\circ} \mathrm{C}$ 
caused the swelling ratios to be decreased. This is due to the collapse of the hydrogel pores at higher temperatures.

Because of their $\mathrm{pH}$-responsive behaviors, the synthesized hydrogels are promising candidates for drug delivery. Accordingly, the ability of the synthesized IPN hydrogels for the controlled delivery of curcumin was investigated. Curcumin was loaded by hydrogels using a swelling diffusion approach. Hydrogels with the loaded curcumin are abbreviated as IPN@Cur. The effect of NPs on the drug loading efficiency of the IPN hydrogels is summarized in Figure $4 \mathrm{~d}$. All the hydrogels with the embedded NPs showed the highest loading efficiency for curcumin. Interestingly, the loading efficiency of IPN hydrogels increased after improving their Ag NPs content. The presence of AgNPs inside the hydrogels resulted in holes and consequently the expansion of the hydrogel network and a higher diffusion of drug [6,7]. In contrary to this result, the loading capacity of the IPN hydrogel decreased with increased $\mathrm{ZnO}$ NPs and CuO NPs contents. In fact, a high content of these nanoparticles inside the hydrogels led to the lower swelling of the IPN hydrogel and consequently a lower loading of drug. The release of curcumin from hydrogels with different NPs contents was evaluated at $\mathrm{pH} 2.1$ and $\mathrm{pH} 7.4$ and at $37^{\circ} \mathrm{C}$. As shown in Figure 5a,b, the release rate of curcumin decreased with an increased NPs content. The incorporation of nanoparticles into the hydrogels increased the stability of the loaded curcumin in the networks and led to a slower release of the drug. The release behaviors of curcumin from the synthesized hydrogels were also $\mathrm{pH}$-responsive. The release of the drug from each hydrogel was maximized and minimized at $\mathrm{pH} 7.4$ and $\mathrm{pH}$ 2.1, respectively (Figure 5). These release characteristics could be ascribed to the high compression of the hydrogel network at $\mathrm{pH} 2.1$ that limits the release of curcumin from the hydrogels. The release of curcumin was increased at its natural $\mathrm{pH}$ due to the increased electrostatic repulsions and the reduction of hydrogen bonds between ionic groups. The release behavior was similar to the swelling ratio pattern and suggested that the pore size decreased at $\mathrm{pH} 2.1$.
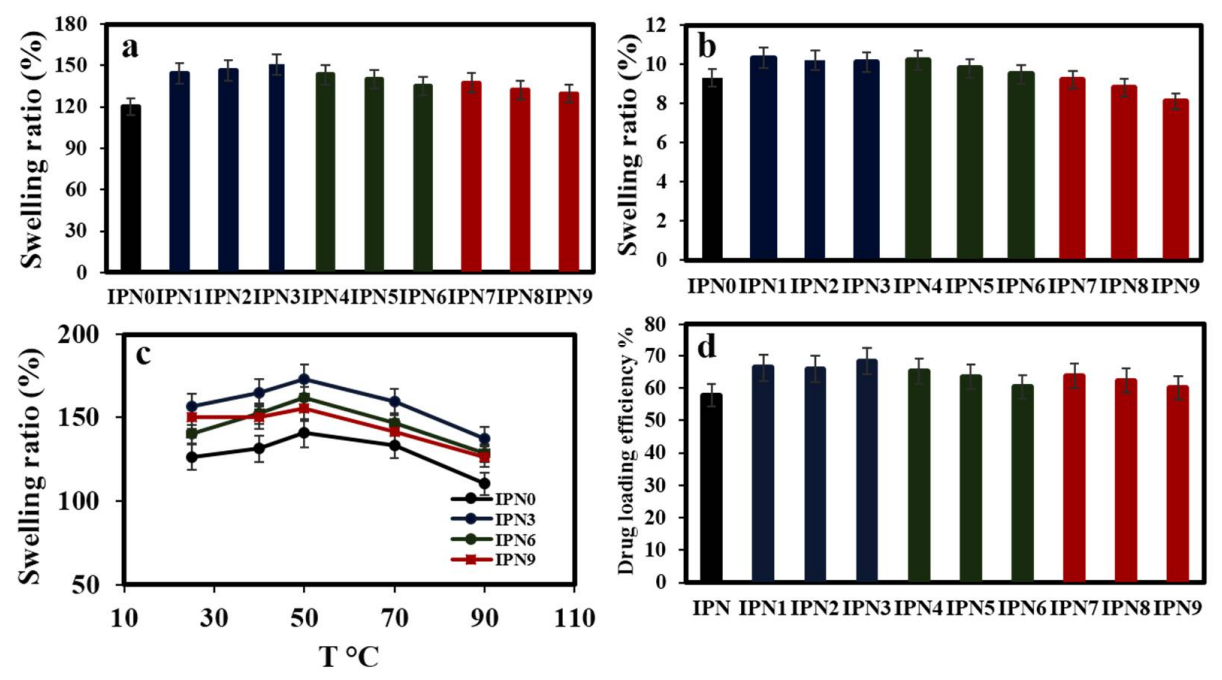

Figure 4. Swelling behavior of different hydrogels at $25^{\circ} \mathrm{C}$ and (a) pH 7.4 and (b) $\mathrm{pH} 2.1$; (c) Swelling behavior of IPNc hydrogels versus temperature at $\mathrm{pH}$ 7.4; (d) Loading efficiency of hydrogels for curcumin.

The mechanism of drug release from the hydrogels at $\mathrm{pH} 7.4$ was evaluated using a Korsmeyer-Peppas model using the equation:

$$
\mathrm{M}_{\mathrm{t}} / \mathrm{M}_{\infty}=\mathrm{K}^{\mathrm{n}}
$$

where $M_{t}$ and $M_{\infty}$ are the amount of the drug released at time $t$ and at infinite time, respectively, and $\mathrm{K}$ and $\mathrm{n}$ are the release rate constant and the release exponent, respectively. 
The values of $K$ and ' $n$ ' along with the values of the correlation coefficient, $r$, are shown in Table 2 . The $\mathrm{K}$ values decreased in the presence of nanoparticles, especially ZnO NPs. The K values ranging from 0.1 to 0.01 indicated the prolonged release of curcumin from the hydrogels. These values suggested that the release of drug from the hydrogels is diffusion-controlled and approximately close to the Korsmeyer-Peppas model [42,46]. The role of graphene sheets, which show a high $\pi-\pi$ interaction with curcumin, in the prolongation of drug release should not be ignored [46].
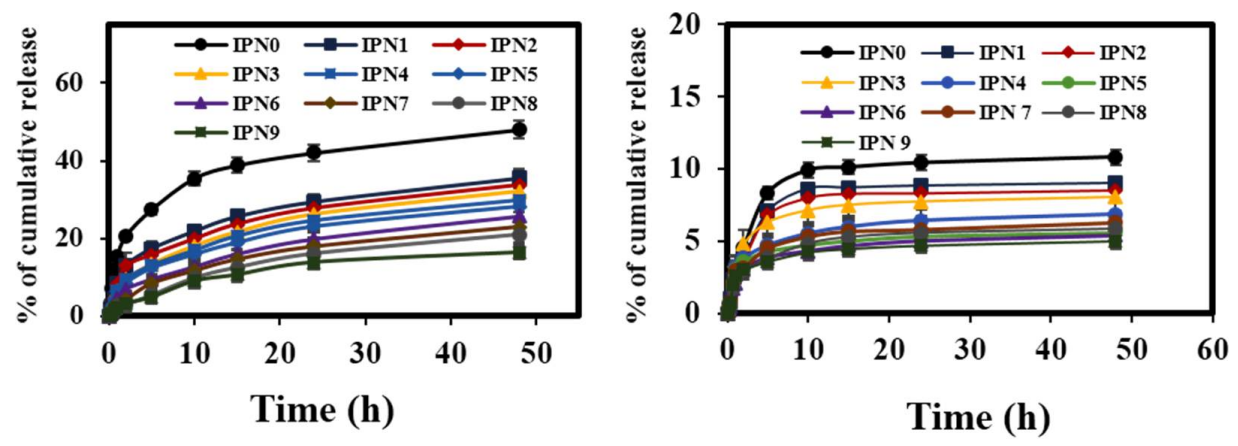

Figure 5. Release profile of curcumin from IPNs (a) pH 2.1 and (b) 7.4.

Table 2. Drug release data of the hydrogels by Korsmeyer-Peppas (K-P) at pH 7.4.

\begin{tabular}{ccccc}
\hline Formulation Code & \% Drug Loading & $\mathbf{K}, \mathbf{h}^{\mathbf{n r}}$ & $\mathbf{n}$ & $\mathbf{R}^{\mathbf{2}}$ \\
\hline IPN0 & 57.7 & 0.1023 & 0.478 & 0.999 \\
IPN1 & 67.3 & 0.0403 & 0.740 & 0.998 \\
IPN2 & 65.3 & 0.401 & 0.711 & 0997 \\
IPN3 & 70.1 & 0.3721 & 0.955 & 0.997 \\
IPN4 & 67.2 & 0.03372 & 0.938 & 0.997 \\
IPN5 & 64.45 & 0.03483 & 0.933 & 0.997 \\
IPN6 & 60.3 & 0.03167 & 1.051 & 0.997 \\
IPN7 & 65.3 & 0.01702 & 1.257 & 0.998 \\
IPN8 & 62.3 & 0.01661 & 1.303 & 0.997 \\
IPN9 & 60.01 & 0.01521 & 1.330 & 0.998 \\
\hline
\end{tabular}

The antibacterial activity of hydrogels against Gram-positive bacteria (S. aureus) and Gram-negative (E. coli) was examined after exposing the bacteria cells $\left(10^{6}\right.$ to $\left.10^{7} \mathrm{CFU} / \mathrm{mL}\right)$ to the same amount $(20 \mathrm{mg})$ of IPN hydrogels in isotonic saline solution for $12 \mathrm{~h}$ under $250 \mathrm{rpm}$ shaking speed. The antibacterial activity of the IPN hydrogels was evaluated using the colony count method (Figure 6). The viability of $E$. coli cells decreased by $12.3 \%, 67.3 \%, 60.4 \%, 56.4 \%, 65.3 \%, 74.21 \%, 66.3 \%$, and $62.5 \%$, and the viability of $S$. aureus cells decreased by $10.3 \%, 29.21 \%, 20.25 \%, 18.51 \%, 55.7 \%, 40.12 \%, 28.8 \%$, and 28.07\% after incubating them with IPN0, IPN2, IPN5, IPN8, IPN@Cur, IPN2@Cur, IPN5@Cur, and IPN8@Cur aqueous suspensions, respectively. Clearly, IPN NPs and IPN NPs@Cur show higher antibacterial activity against Gram-negative than Gram-positive bacteria. The antibacterial activity of hydrogels against Gram-negative bacteria could be due to the stronger electrostatic interactions between positively charged metal ions and this type of bacteria [31].

As expected, bacteriostatic behavior was not observed for the pure IPN hydrogels, and colonies easily formed on the pure hydrogel surfaces. However, there was a bacterial growth reduction caused by hydrogels containing NPs. Graphene oxide as the platform for growing metal nanoparticles and stabilizing them due to its large specific surface and area lateral dimension, could increase the availability of bacteria on the antibacterial materials by the adsorption of the bacteria species. IPN containing Ag NPs exhibited higher antimicrobial effects against $E$. coli than those with embedded $\mathrm{ZnO}$ and $\mathrm{CuO}$ NPs. Most significantly, the immobilization of curcumin also is further expected to enhance such activities in the IPN0 and IPN NP hydrogels. These results were expected because 
curcumin has shown antimicrobial activity against a wide range of bacteria [47,48]. Surprisingly, the antibacterial activity of the synthesized hydrogels containing curcumin were in line with the drug release trend. In other words, the antibacterial activity of the hydrogels containing drugs was affected by the release rate of the drug. IPN0 hydrogels showed the greatest effect of the drug against bacteria due to the high release of curcumin. In fact, depending on the speed of drug release and NP release (Figure S9), hydrogels containing nanoparticles and curcumin with a synergistic effect showed a different activity on antibacterial activity. To further investigate the antibacterial behavior of IPN@Cur, the morphology of bacteria incubated with this hydrogel was investigated by field emission (FE)-SEM (Figure 6). After treatment with IPN2@Cur for $12 \mathrm{~h}$, the shape of bacteria changed significantly and their membrane was damaged. Clearly, the toxicity of the synthesized hydrogels was due to the synergistic effect of the NPs, graphene, and curcumin $[49,50]$.
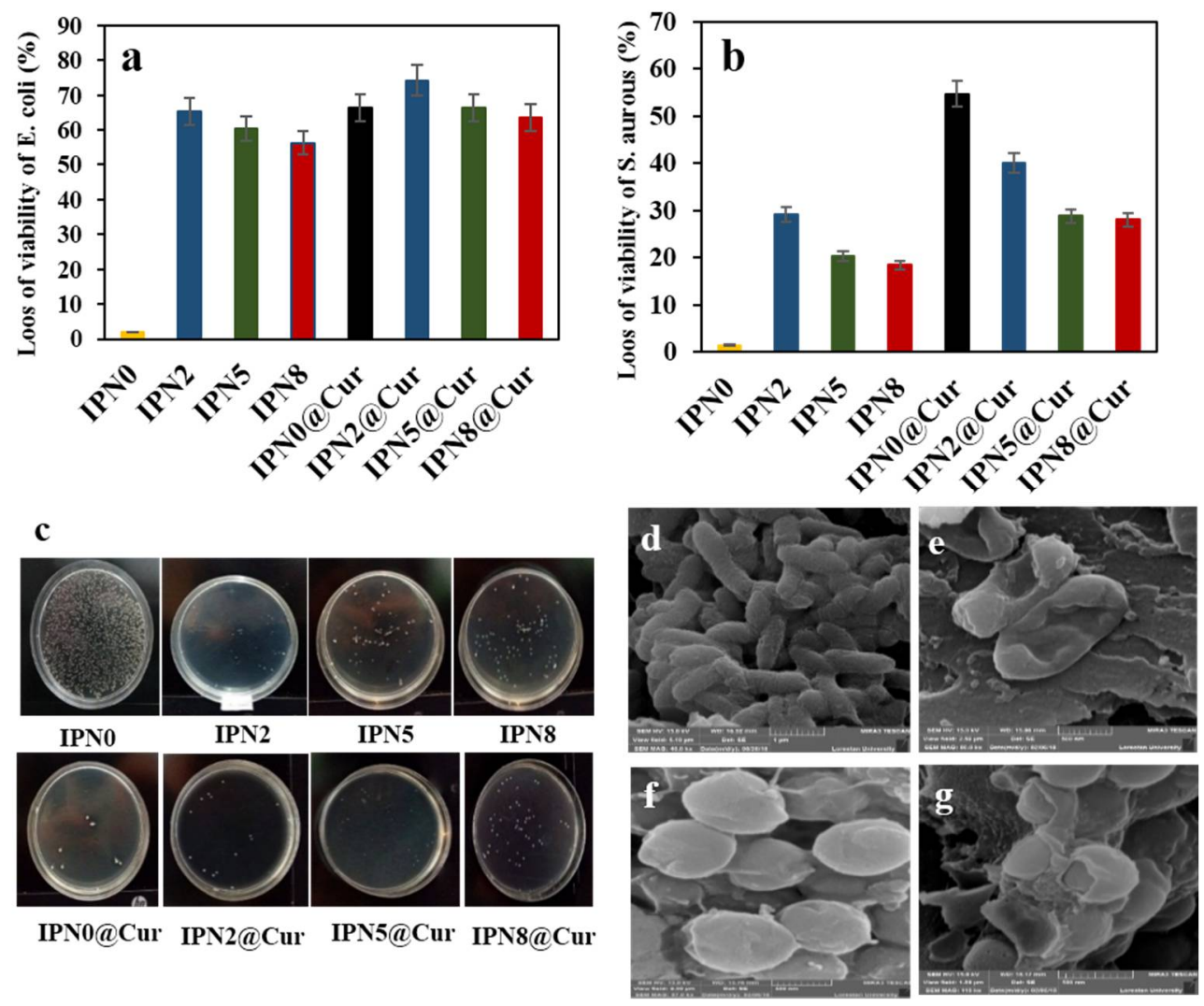

Figure 6. The viability of (a) E. coli cells $\left(10^{6}-10^{7} \mathrm{CFU} / \mathrm{mL}\right)$ and (b) S. aureus cells $\left(10^{6}-10^{7} \mathrm{CFU} / \mathrm{mL}\right)$ incubated with hydrogels $(2 \mathrm{mg}$ ) for $12 \mathrm{~h}$; (c) Photograph of E. coli colonies grown on agar plates after exposure to IPN hydrogels. SEM images of $E$. coli after incubation with (d) saline solution and (e) IPN2@Cur for 12 h. SEM images of S. aureus after incubation with (f) saline solution and (g) IPN2@Cur for $12 \mathrm{~h}$.

\section{Conclusions}

In summary, hybrid hydrogels consisting of IPN, PAsp, graphene, and metal nanoparticles were synthesized and their antibacterial activity and drug delivery application was investigated. Results showed that NPs have a significant effect on the loading capacity and antibacterial activity of the synthesized hydrogels. Furthermore, the antibacterial activity of the hydrogels depended on the type of metal nanoparticle, the rate of release of curcumin, as well as the type of bacteria. Due the synergic effects of different components, the synthesized hydrogels could be used for a wide range of biomedical applications. 
Supplementary Materials: The following supplementary materials are available online at http://www.mdpi. com/2073-4360/10/6/660/s1.

Author Contributions: M.A. and A.D.T. conceived and designed the experiments, supervised and coordinated all activities throughout this work. S.S. performed the experiments. M.A., A.D.T. and S.S. analyzed the data and wrote the paper.

Acknowledgments: The authors would like to acknowledge the financial support of Lorestan University.

Conflicts of Interest: The authors declare no conflict of interest.

\section{References}

1. Xu, L.; Qiu, L.; Sheng, Y.; Sun, Y.; Deng, L.; Li, X.; Bradley, M.; Zhang, R. Biodegradable pH-responsive hydrogels for controlled dual-drug release. J. Mater. Chem. B 2018. [CrossRef]

2. Mohammadifar, E.; Kharat, A.N.; Adeli, M. Targeted multifunctional redox-sensitive micelles co-delivery of DNA and doxorubicin for treatment of breast cancer. J. Mater. Chem. B 2015, 3, 3896-3921. [CrossRef]

3. Gaharwar, A.K.; Peppas, N.A.; Khademhosseini, A. Nanocomposite hydrogels for biomedical applications. Biotechnol. Bioeng. 2014, 111, 441-453. [CrossRef] [PubMed]

4. Hoare, T.R.; Kohane, D.S. Hydrogels in drug delivery: Progress and challenges. Polymer 2008, 49, $1993-2007$. [CrossRef]

5. Sahraei, R.; Ghaemy, M. Synthesis of modified gum tragacanth/graphene oxide composite hydrogel for heavy metal ions removal and preparation of silver nanocomposite for antibacterial. Carbohydr. Polym. 2017, 157, 823-833. [CrossRef] [PubMed]

6. Pathania, D.; Gupta, D.; Agarwal, S.; Asif, M.; Gupta, V.K. Fabrication of chitosan-g-poly(acrylamide)/CuS nanocomposite for controlled drug delivery and antibacterial activity. Mater. Sci. Eng. C 2016, 64, 428-435. [CrossRef] [PubMed]

7. Lima-Tenório, M.K.; Tenorio-Neto, E.T.; Garcia, F.P.; Nakamura, C.V.; Guilherme, M.R.; Muniz, E.C.; Pineda, E.A.; Rubira, A.F. Hydrogel nanocomposite based on starch and Co-doped zinc ferrite nanoparticles that shows magnetic field-responsive drug release changes. J. Mol. Liq. 2015, 210, 100-105. [CrossRef]

8. Thoniyot, P.; Tan, M.J.; Karim, A.A.; Young, D.J.; Loh, X.J. Nanoparticle-hydrogel composites: Concept, design, and applications of these promising, multi-functional materials. Adv. Sci. 2015, 2. [CrossRef] [PubMed]

9. Merino, S.; Martín, C.; Kostarelos, K.; Prato, M.; Vázquez, E. Nanocomposite hydrogels: 3D polymer-nanoparticle synergies for on-demand drug delivery. ACS Nano 2015, 9, 4686-4697. [CrossRef] [PubMed]

10. De Koker, S.; Cui, J.; Vanparijs, N.; Albertazzi, L.; Grooten, J.; Caruso, F.; de Geest, B.G. Engineering Polymer Hydrogel Nanoparticles for Lymph Node-Targeted Delivery. Angew. Chem. Int. Ed. 2016, 55, 1334-1339. [CrossRef] [PubMed]

11. Zhou, Y.; Damasceno, P.F.; Somashekar, B.S.; Engel, M.; Tian, F.; Zhu, J.; Huang, R.; Johnson, K.; McIntyre, C.; Sun, K. Unusual multiscale mechanics of biomimetic nanoparticle hydrogels. Nat. Commun. 2018, 9, 181. [CrossRef] [PubMed]

12. Baumann, B.; Jungst, T.; Stichler, S.; Feineis, S.; Wiltschka, O.; Kuhlmann, M.; Lindén, M.; Groll, J. Control of Nanoparticle Release Kinetics from 3D Printed Hydrogel Scaffolds. Angew. Chem. Int. Ed. 2017, 56, 4623-4628. [CrossRef] [PubMed]

13. Zhao, J.; Zhao, X.; Guo, B.; Ma, P.X. Multifunctional interpenetrating polymer network hydrogels based on methacrylated alginate for the delivery of small molecule drugs and sustained release of protein. Biomacromolecules 2014, 15, 3246-3252. [CrossRef] [PubMed]

14. Dragan, E.S. Chemical Engineering Journal, Design and applications of interpenetrating polymer network hydrogels. Rapra Rev. Rep. 2014, 243, 572-590.

15. Wang, J.; Hu, H.; Yang, Z.; Wei, J.; Li, J. IPN hydrogel nanocomposites based on agarose and ZnO with antifouling and bactericidal properties. Mater. Sci. Eng. C 2016, 61, 376-386. [CrossRef] [PubMed]

16. Basu, S.; Samanta, H.S.; Ganguly, J. Green synthesis and swelling behavior of Ag-nanocomposite semi-IPN hydrogels and their drug delivery using Dolichos biflorus Linn. Soft Mater. 2018, 16, 7-19. [CrossRef] 
17. Meng, H.; Zhang, X.; Chen, Q.; Wei, J.; Wang, Y.; Dong, A.; Yang, H.; Tan, T.; Cao, H. Preparation of poly(aspartic acid) superabsorbent hydrogels by solvent-free processes. J. Polym. Eng. 2015, 35, $647-655$. [CrossRef]

18. Gyarmati, B.; Vajna, B.; Némethy, Á.; László, K.; Szilágyi, A. Redox-and pH-Responsive Cysteamine-Modified Poly(aspartic acid) Showing a Reversible Sol-Gel Transition. Macromol. Biosci. 2013, 13, 633-640. [CrossRef] [PubMed]

19. Wang, Y.; Hou, Y.; Ruan, G.; Pan, M.; Liu, T. Study on the polymerization of aspartic acid catalyzed by phosphoric acid. J. Macromol. Sci. Part A Pure Appl. Chem. 2003, 40, 293-307. [CrossRef]

20. Marcano, D.C.; Kosynkin, D.V.; Berlin, J.M.; Sinitskii, A.; Sun, Z.; Slesarev, A.; Alemany, L.B.; Lu, W.; Tour, J.M.; Marcano, D.C.; et al. Improved synthesis of graphene oxide. ACS Nano 2010, 4, 4806-4814. [CrossRef] [PubMed]

21. Samadaei, F.; Salami-Kalajahi, M.; Roghani-Mamaqani, H.; Banaei, M. A structural study on ethylenediamine-and poly(amidoamine)-functionalized graphene oxide: Simultaneous reduction, functionalization, and formation of 3D structure. RSC Adv. 2015, 5, 71835-71843. [CrossRef]

22. Ai, L.; Jiang, J. Catalytic reduction of 4-nitrophenol by silver nanoparticles stabilized on environmentally benign macroscopic biopolymer hydrogel. Bioresour. Technol. 2013, 132, 374-377. [CrossRef] [PubMed]

23. Gil, J.; Natesan, S.; Li, J.; Valdes, J.; Harding, A.; Solis, M.; Davis, S.C.; Christy, R.J. A PEGylated fibrin hydrogel-based antimicrobial wound dressing controls infection without impeding wound healing. Int. Wound J. 2017, 14, 1248-1257. [CrossRef] [PubMed]

24. Ganguly, S.; Mondal, S.; Das, P.; Bhawal, P.; Maity, P.P.; Ghosh, S.; Dhara, S.; Das, N.C. Design of psyllium-g-poly(acrylic acid-co-sodium acrylate)/cloisite 10A semi-IPN nanocomposite hydrogel and its mechanical, rheological and controlled drug release. Int. J. Biol. Macromol. 2018, 111, 983-998. [CrossRef] [PubMed]

25. Jokar, S.; Pourjavadi, A.; Adeli, M. Albumin-graphene oxide conjugates; carriers for anticancer drugs. RSC Adv. 2014, 4, 33001-33006. [CrossRef]

26. Wang, P.; Wu, Q.; Han, L.; Wang, S.; Fang, S.; Zhang, Z.; Sun, S. Synthesis of conjugated covalent organic frameworks/graphene composite for supercapacitor electrodes. RSC Adv. 2015, 5, 27290-27294. [CrossRef]

27. Gong, C.; Lu, C.; Li, B.; Shan, M.; Wu, G. Injectable dopamine-modified poly $(\alpha, \beta$-aspartic acid) nanocomposite hydrogel as bioadhesive drug delivery system. J. Biomed. Mater. Res. Part A 2017, 105, 1000-1008. [CrossRef] [PubMed]

28. Lim, S.L.; Tang, W.N.H.; Ooi, C.W.; Chan, E.S.; Tey, B.T. Rapid swelling and deswelling of semi-interpenetrating network poly(acrylic acid)/poly(aspartic acid) hydrogels prepared by freezing polymerization. J. Appl. Polym. Sci. 2016, 133. [CrossRef]

29. Alshehri, S.M.; Aldalbahi, A.; Al-Hajji, A.B.; Chaudhary, A.A.; Alhokbany, N.; Ahamad, T. Development of carboxymethyl cellulose-based hydrogel and nanosilver composite as antimicrobial agents for UTI pathogens. Carbohydr. Polym. 2016, 138, 229-236. [CrossRef] [PubMed]

30. Di, Z.; Shi, Z.; Ullah, M.W.; Li, S.; Yang, G. A transparent wound dressing based on bacterial cellulose whisker and poly(2-hydroxyethyl methacrylate). Int. J. Biol. Macromol. 2017, 105, 638-644. [CrossRef] [PubMed]

31. Oun, A.A.; Rhim, J.-W. Carrageenan-based hydrogels and films: Effect of $\mathrm{ZnO}$ and CuO nanoparticles on the physical, mechanical, and antimicrobial properties. Food Hydrocoll. 2017, 67, 45-53. [CrossRef]

32. Yang, J.; Tan, W.; Chen, C.; Tao, Y.; Qin, Y.; Kong, Y. Nonenzymatic glucose sensing by CuO nanoparticles decorated nitrogen-doped graphene aerogel. Mater. Sci. Eng. C 2017, 78, 210-217. [CrossRef] [PubMed]

33. Schwartz, V.B.; Thétiot, F.; Ritz, S.; Pütz, S.; Choritz, L.; Lappas, A.; Förch, R.; Landfester, K.; Jonas, U. Antibacterial surface coatings from zinc oxide nanoparticles embedded in poly( $N$-isopropylacrylamide) hydrogel surface layers. Adv. Funct. Mater. 2012, 22, 2376-2386. [CrossRef]

34. Mirzaei, H.; Darroudi, M. Zinc oxide nanoparticles: Biological synthesis and biomedical applications. Ceram. Int. 2017, 43, 907-914. [CrossRef]

35. Han, D.-M.; Zhang, Q.M.; Serpe, M.J. Poly(N-isopropylacrylamide)-co-(acrylic acid) microgel/Ag nanoparticle hybrids for the colorimetric sensing of $\mathrm{H}_{2} \mathrm{O}_{2}$. Nanoscale 2015, 7, 2784-2789. [CrossRef] [PubMed]

36. Kaur, A.; Mann, S.; Goyal, B.; Pal, B.; Goyal, D. CuO nanostructures of variable shapes as an efficient catalyst for [3 + 2] cycloaddition of azides with terminal alkyne. RSC Adv. 2016, 6, 102733-102743. [CrossRef]

37. Hou, X.; Wang, L. Controllable fabrication and photocatalysis of $\mathrm{ZnO} / \mathrm{Au}$ nanohybrids via regenerative ion exchange and reduction cycles. RSC Adv. 2014, 4, 56945-56951. [CrossRef] 
38. Vacchi, I.A.; Spinato, C.; Raya, J.; Bianco, A.; Ménard-Moyon, C. Chemical reactivity of graphene oxide towards amines elucidated by solid-state NMR. Nanoscale 2016, 8, 13714-13721. [CrossRef] [PubMed]

39. Ahamed, M.N.; Sankar, S.; Kashif, P.M.; Basha, S.H.; Sastry, T. Evaluation of biomaterial containing regenerated cellulose and chitosan incorporated with silver nanoparticles. Int. J. Biol. Macromol. 2015, 72, 680-686. [CrossRef] [PubMed]

40. Javed, R.; Ahmed, M.; Haq, I.u.; Nisa, S.; Zia, M. PVP and PEG doped CuO nanoparticles are more biologically active: Antibacterial, antioxidant, antidiabetic and cytotoxic perspective. Mater. Sci. Eng. C 2017, 79, 108-115. [CrossRef] [PubMed]

41. Vijayalakshmi, K.; Sivaraj, D. Enhanced antibacterial activity of Cr doped ZnO nanorods synthesized using microwave processing. RSC Adv. 2015, 5, 68461-68469. [CrossRef]

42. Dragan, E.S.; Cocarta, A.I. Smart macroporous IPN hydrogels responsive to $\mathrm{pH}$, temperature, and ionic strength: Synthesis, characterization, and evaluation of controlled release of drugs. ACS Appl. Mater. Interfaces 2016, 8, 12018-12030. [CrossRef] [PubMed]

43. Yadollahi, M.; Farhoudian, S.; Namazi, H. One-pot synthesis of antibacterial chitosan/silver bio-nanocomposite hydrogel beads as drug delivery systems. Int. J. Biol. Macromol. 2015, 79, 37-43. [CrossRef] [PubMed]

44. Yadollahi, M.; Farhoudian, S.; Barkhordari, S.; Gholamali, I.; Farhadnejad, H.; Motasadizadeh, H. Facile synthesis of chitosan/ZnO bio-nanocomposite hydrogel beads as drug delivery systems. Int. J. Biol. Macromol. 2016, 82, 273-278. [CrossRef] [PubMed]

45. Yadollahi, M.; Gholamali, I.; Namazi, H.; Aghazadeh, M. Synthesis and characterization of antibacterial carboxymethylcellulose/ $\mathrm{CuO}$ bio-nanocomposite hydrogels. Int. J. Biol. Macromol. 2015, 73, 109-114. [CrossRef] [PubMed]

46. Wang, J.; Liu, C.; Shuai, Y.; Cui, X.; Nie, L. Controlled release of anticancer drug using graphene oxide as a drug-binding effector in konjac glucomannan/sodium alginate hydrogels. Colloids Surf. B 2014, 113, $223-229$. [CrossRef] [PubMed]

47. Shlar, I.; Droby, S.; Rodov, V. Modes of antibacterial action of curcumin under dark and light conditions: A toxicoproteomics approach. J. Proteom. 2017, 160, 8-20. [CrossRef] [PubMed]

48. Yang, X.X.; Li, C.M.; Huang, C.Z. Curcumin modified silver nanoparticles for highly efficient inhibition of respiratory syncytial virus infection. Nanoscale 2016, 8, 3040-3048. [CrossRef] [PubMed]

49. Tu, Z.; Achazi, K.; Schulz, A.; Mülhaupt, R.; Thierbach, S.; Rühl, E.; Adeli, M.; Haag, R. Combination of Surface Charge and Size Controls the Cellular Uptake of Functionalized Graphene Sheets. Adv. Funct. Mater. 2017, 27. [CrossRef]

50. Tsekova, P.B.; Spasova, M.G.; Manolova, N.E.; Markova, N.D.; Rashkov, I.B. Electrospun curcumin-loaded cellulose acetate/polyvinylpyrrolidone fibrous materials with complex architecture and antibacterial activity. Mater. Sci. Eng. C 2017, 73, 206-214. [CrossRef] [PubMed] 